\title{
Article \\ Crushing of Double-Walled Corrugated Board and Its Influence on the Load Capacity of Various Boxes
}

\author{
Tomasz Gajewski ${ }^{1, *(\mathbb{D}}$, Tomasz Garbowski ${ }^{2}{ }^{\mathbb{D}}$, Natalia Staszak $^{3}$ and Małgorzata Kuca ${ }^{4}$ \\ 1 Institute of Structural Analysis, Poznan University of Technology, Piotrowo 5, 60-965 Poznań, Poland \\ 2 Department of Biosystems Engineering, Poznan University of Life Sciences, Wojska Polskiego 50, \\ 60-627 Poznań, Poland; tomasz.garbowski@up.poznan.pl \\ 3 Reserach and Development Department, FEMat Sp. z o.o., Romana Maya 1, 61-371 Poznań, Poland; \\ natalia.staszak@fematproject.pl \\ 4 Schumacher Packaging Sp. z o.o., Wrocławska 66, 55-330 Krępice, Poland; \\ malgorzta.kuca@schumacher-packaging.com.pl \\ * Correspondence: tomasz.gajewski@put.poznan.pl
}

Citation: Gajewski, T.; Garbowski, T.; Staszak, N.; Kuca, M. Crushing of Double-Walled Corrugated Board and Its Influence on the Load Capacity of Various Boxes. Energies 2021, 14, 4321. https://doi.org/ $10.3390 /$ en14144321

Academic Editors: Claudio Mele and José A.F.O. Correia

Received: 18 May 2021

Accepted: 15 July 2021

Published: 17 July 2021

Publisher's Note: MDPI stays neutral with regard to jurisdictional claims in published maps and institutional affiliations.

Copyright: (c) 2021 by the authors. Licensee MDPI, Basel, Switzerland. This article is an open access article distributed under the terms and conditions of the Creative Commons Attribution (CC BY) license (https:// creativecommons.org/licenses/by/ $4.0 /)$.

\begin{abstract}
As long as non-contact digital printing remains an uncommon standard in the corrugated packaging industry, corrugated board crushing remains a real issue that affects the load capacity of boxes. Crushing mainly occurs during the converting of corrugated board (e.g., analog flexographic printing or laminating) and is a process that cannot be avoided. However, as this study shows, it can be controlled. In this work, extended laboratory tests were carried out on the crushing of double-walled corrugated board. The influence of fully controlled crushing (with a precision of $\pm 10 \mu \mathrm{m}$ ) in the range from 10 to $70 \%$ on different laboratory measurements was checked. The typical mechanical tests-i.e., edge crush test, four-point bending test, shear stiffness test, torsional stiffness test, etc.-Were performed on reference and crushed specimens. The residual thickness reduction of the crushed samples was also controlled. All empirical observations and performed measurements were the basis for building an analytical model of crushed corrugated board. The proven and verified model was then used to study the crushing effect of the selected corrugated board on the efficiency of simple packages with various dimensions. The proposed measurement technique was successfully used to precisely estimate and thus control the crushing of corrugated board, while the proposed numerical and analytical techniques was used to estimate the load capacity of corrugated board packaging. A good correlation between the measured reduced stiffness of the corrugated cardboard and the proposed analytical predictive models was obtained.
\end{abstract}

Keywords: corrugated cardboard; converting; crushing; numerical homogenization; strain energy equivalence; finite element method; shell structures; transverse shear

\section{Introduction}

Corrugated cardboard packaging is one of the most common ways to protect various goods during storage, transportation and delivery or shop exposition. The current trend in developed and moderately developed countries is to consume various goods, from household products to food, clothing, automotive elements, etc. Thus, corrugated cardboard packaging is growing in popularity and application. The packaging must be tailored to particular goods, i.e., it must have adequate geometry and strength, and also sometimes requires additional features, such as holes [1,2], perforations [3], a specific shape [4], inserts/dividers or locking tabs.

The double-walled corrugated boards considered in this study are used in large collective packaging for large products, so they must protect the goods from accidental mechanical damage and withstand their large mass. Often, to elevate the corrugated board packaging, kraftliner papers are used for boards. These papers, unlike testliner papers, contain a small amount of recycled fibres $[5,6]$. The products packed with boxes using 
double-walled corrugated cardboards include electrical household appliances, such as televisions, washing machines, refrigerators and furniture components, in addition to some more fragile items such as glass bottles, perfumes and automotive parts. Depending on the application, the outer layer may be natural, or the boards may have one or two white sides. Double-walled boards are created from five paperboards, three liners (flat layers) and two fluting layers. The most common composition for double walls is formed from BC (5-7 mm), EB (3.5-5 mm) or EC (4-5.5 mm) flutes. The grammage of the corrugated boards is usually $550-900 \mathrm{~g} / \mathrm{mm}^{2}$, but 480 or $1300 \mathrm{~g} / \mathrm{mm}^{2}$ can also be found on the market.

Double-walled corrugated cardboards have been used for many years to design packaging [7-9]. The analytical methods used to determine the packaging strength do not differentiate between single- and double-walled cases [10-15]. These methods take into consideration selected mechanical properties of the cardboard derived from mechanical tests, such as the edge crush test (ECT) [16] or the torsion test [17,18]. Thus, these analytical methods, whether simple (such as the well-known McKee formula [11]) or more advanced (such as our recently published one [15]), may be used to estimate the box compression test (BCT) output. This advanced approach takes into consideration the transverse shear stiffness [17-23], which seems to be essential to include in any estimate of the strength of converted cardboards, as shown in our recent paper [24].

In the converting processes-i.e., printing, laminating, die-cutting, etc.- - the crushing of the corrugated cardboard is observed [6]. If the crushing is severe, the delamination of the paper of fluting would appear, as presented in [25]. In single-walled corrugated boards, the fluting shape transforms into a characteristic trapezoidal form, as shown in experimental $[19,26]$ and numerical [24] studies. To the best of our knowledge, in doublewalled corrugated boards, this crushing has not been studied. Since elevated strength is crucial in double-walled corrugated boards, the crushing effect must be considered to ensure the proper strength specification of the packaging.

As discussed above, the crushing effect significantly decreases the mechanical properties in single-walled corrugated cardboards [24]. The decrease in the ECT index of corrugated board is small due to the preservation of the material area, which in most cases influences the ECT index [16]. In torsion or bending, the stiffness decrease is more severe due to crushing, since the cardboard quickly recovers its crushed geometry (a trapezoidlike form). The more trapezoidal the form, the more the thickness decreases. Decreased thickness due to a small moment of inertia causes a high sensitivity of torsion and bending to crushing. The above discussion seems straightforward and clear for single-walled corrugated cardboards, but for double-walled cardboard, some additional issues may appear. For instance, double-walled boards have a fluting period of two flutings, and thus they can exhibit a local in-span bending of the internal liner, or a more complex shape than the simple trapezoidal form that appears when single-walled boards are crushed. These effects have not been studied in the literature, but in corrugated cardboard processing, they have been well known for a few years.

From an industry 4.0 point of view, more information on the crushing of cardboard material during production due to different technological processes would enhance quality control significantly. Optimal solutions and savings for box designs are available due to advanced mathematical modelling; this may be related to a single-box feature $[1,3]$ or to a more heuristic approach to design $[27,28]$. Currently, practitioners know that crushed material is weaker, but they do not have the techniques, tools or models to measure how much or which technological process is the most crucial here. Thus, this study verifies which typical, mechanical tests of corrugated cardboard have the greatest potential to identify the crushing level of double-walled boards through a series of experimental tests on corrugated cardboard samples, using samples with induced levels of crushing. Moreover, it demonstrates numerically how much the performance of double-walled boards declines if particular levels of crushing are obtained and how significant this effect is. The results obtained and the experimental observations may serve as a guide for designers of packaging with analogue prints or laminated boxes, and the proposed 
analytical model for crushed corrugated board may be used to better predict the load capacity of ecological packages.

\section{Materials and Methods}

\subsection{Mechanical Tests of Corrugated Cardboard}

Various tests can be conducted to determine the stiffness and strength of a corrugated board. The mechanical tests often performed in cardboard packaging laboratories are: (a) stiffness in the four-point bending test (BNT), (b) ECT, (c) shear stiffness testing (SST) and (d) torsional stiffness testing (TST). All of these tests can be performed using a single laboratory machine called the BSE System from Femat [29].

The BNT is a laboratory test in which the bending stiffness is measured (see Figure 1). Samples of $50 \mathrm{~mm} \times 250 \mathrm{~mm}$ are usually used for this kind of test. Due to the static scheme of the specimen, a constant moment and zero shear force between the internal supports are obtained. As a result, the influence of transverse shear stiffness on the half-span deflection of the sample can be eliminated, and the observations of its bending stiffness are more accurate. Shear force is still present between the outer and inner supports. Sample damage (fracture and/or crushing) has a significant impact on the bending stiffness measurement. Thus, for samples with more than 50\% crushing, the results are unreliable.

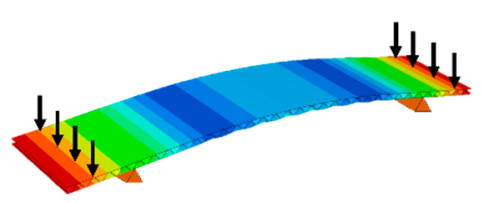

(a)

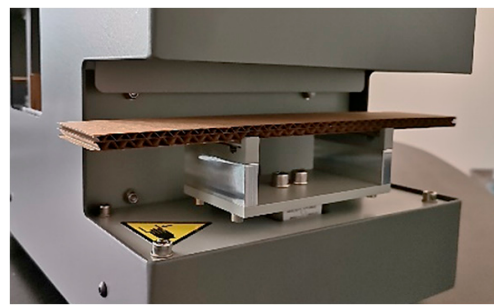

(b)

Figure 1. The four-point bending test (BNT): (a) loaded and deformed specimen; (b) cardboard testing device.

The compressive strength of the specimen is determined in the ECT (see Figure 2). The ECT is one of the most important and recognizable tests of corrugated board from a practical point of view. The test is carried out on specimens of $25 \mathrm{~mm} \times 100 \mathrm{~mm}$ that are usually thicker than $1 \mathrm{~mm}$. Note that when testing a slender sample (e.g., corrugated board with $\mathrm{E}$ and $\mathrm{F}$ flute), the primary failure mechanism is loss of stability and not (as the name of the test suggests) crushing.

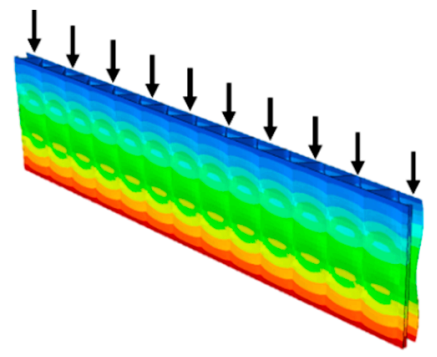

(a)

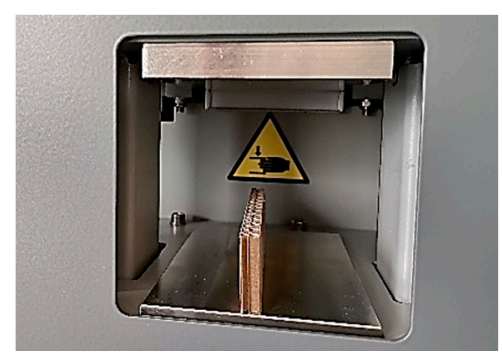

(b)

Figure 2. The edge crush test (ECT): (a) loaded and deformed specimen; (b) cardboard testing device.

The SST is conducted by twisting a sample of corrugated board with dimensions of $80 \mathrm{~mm} \times 80 \mathrm{~mm}$ using a pair of forces (see Figure 3). During the test, a known displacement is applied at two corners of a rectangular sample (two points on a diagonal), and the displacement at the other two corners is measured. This allows researchers to determine 
the shear stiffness of the cardboard. The linear load-displacement relationship is used to determine the stiffness of the sample. Crushing of the sample (i.e., thickness reduction) has a significant effect on the SST results.

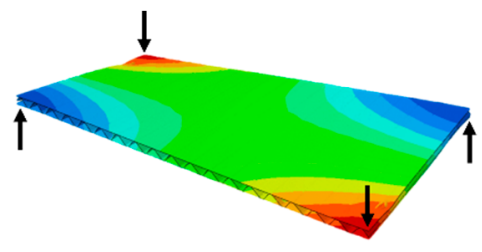

(a)

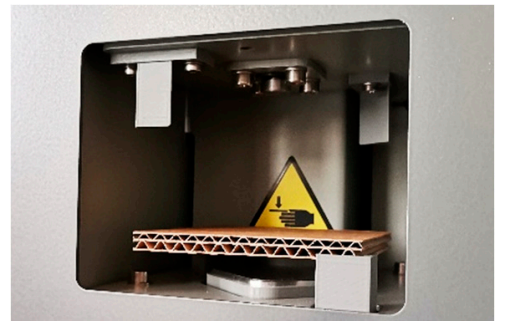

(b)

Figure 3. The shear stiffness test (SST): (a) loaded and deformed specimen; (b) cardboard testing device.

The torsional stiffness test (TST) is based on twisting a sample of $25 \mathrm{~mm} \times 150 \mathrm{~mm}$ by a few degrees in both directions (see Figure 4). The linear part of a curve describing the angle of rotation with respect to the bending moment is used to specify the torsional stiffness of the specimen. The guarantees of reliable results are: (i) a static method of measuring the angle of torque and rotation, (ii) a stable method of holding the specimen and (iii) a relatively large width of the sample. Reliable results in the TST can be obtained even for very deteriorated and crushed specimens.

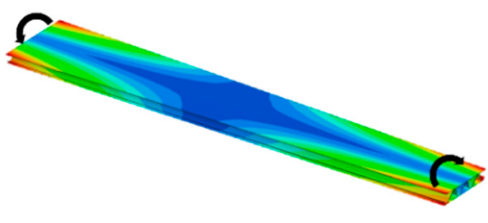

(a)

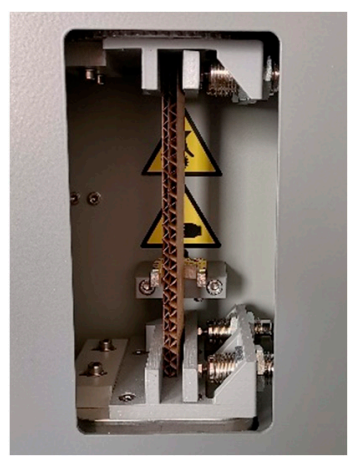

(b)

Figure 4. The torsional stiffness test (TST): (a) loaded and deformed specimen; (b) cardboard testing device.

The crushing device (CRS) from Femat [30] is used to evaluate the influence of processes such as stamping, laminating and analog printing or creasing on the load capacity and on the quality of corrugated board or packaging (see Figure 5). Cardboard crushing can be performed with a CRS in a fully controlled manner, in a range from 10 to $70 \%$ (a level of crush of $10 \%$ means that the original thickness of the cardboard is decreased to $90 \%$ ). 


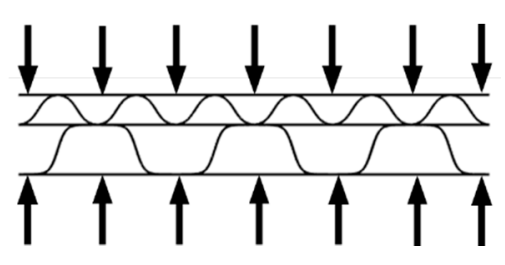

(a)

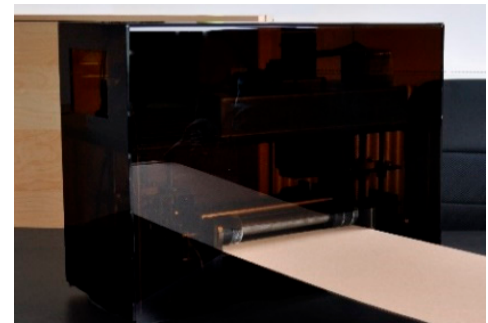

(b)

Figure 5. Cardboard crushing with CRS: (a) loaded and deformed specimen; (b) cardboard testing device.

\subsection{Coefficient of Determination and Estimation Error}

To understand the impact of the crushing of corrugated board on the various mechanical properties measured in different tests, first the correlation between the level of crush and the decrease in the individual measured quantities was investigated. The coefficient of determination $R^{2}$ was calculated for each index of cardboard to determine the relationship between the crushing and the decrease in the corrugated board's stiffness value, according to the formula

$$
R^{2}=1-\frac{\sum_{i=1}^{n}\left(x_{i}-\hat{y}_{i}\right)^{2}}{(n-1) \cdot \operatorname{var}(x)}
$$

where $x_{i}$-the expected ratio of the measured value of the crushed sample to the initial value of the measured parameter (CRS $=0 \% \rightarrow x_{i}=1.0, \mathrm{CRS}=10 \% \rightarrow x_{i}=0.9$, etc.); $\hat{y}_{i}$ - the values computed on the basis of Equation (2) describing the linear regression; $\operatorname{var}(x)$ - the variance of the expected ratio of the measured value of the crushed sample to the initial value,

$$
\hat{y}_{i}=\bar{a}\left(x_{i}-\bar{x}\right)+\bar{y},
$$

where $\bar{x}$-the mean value of the expected ratio of the measured value of the crushed sample to the initial value, $\bar{y}$ - the mean value of the measured quantity (e.g., SST-MD, TST-CD, etc.). Parameter $\bar{a}$ is the slope of the linear regression:

$$
\bar{a}=\frac{\sum_{i=1}^{n}\left(x_{i}-\bar{x}\right)\left(y_{i}-\bar{y}\right)}{\sum_{i=1}^{n}\left(x_{i}-\bar{x}\right)^{2}} .
$$

\subsection{Numerical-Analytical Approach for Modeling Crushing}

In this study, not only were laboratory measurements performed, but extended numerical computations of the double-walled packaging's compressive strength were also conducted, including different levels of crushing. These computations used a similar workflow to that employed in [24]; however, it should be noted that the crushing shape was acquired via a different analytical form because double-walled corrugated cardboard was used. Here, no formal finite element analyses were performed to get the crushed shape. Additionally, the focus of the computations was not the performance of a single corrugated cardboard sample but, rather, the compressive strength of the packaging. The numerical study consists of several steps, presented in Figure 6:

- $\quad$ Building the initial geometry of the intact corrugated cardboard (Stage a);

- Defining the shape of the crushed corrugated cardboard by a numerical-analytical approximation (Stage $\mathrm{a}-\mathrm{b}$ );

- Building the material stiffness matrix using the geometry of crushed corrugated cardboard (Stage c-d);

- Homogenizing the structure to a single layered composite with effective properties according to the method presented by Garbowski and Gajewski [31] (Stage d-e); 
- Computing packaging compressive strength for simple flap boxes with various dimensions via an analytical formula proposed by Garbowski et al. [23], using composite properties acquired in the previous stage (Stage $\mathrm{f}$ ).

(a)

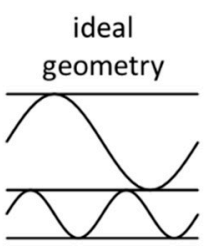

(f)

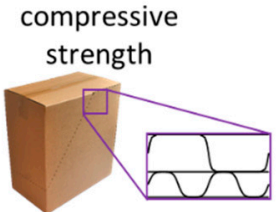

(b)

$$
\underset{\text { crushing }}{\stackrel{\text { analytical }}{\longrightarrow}}
$$

$\underset{\text { estimation }}{\stackrel{\text { analytical }}{\leftarrow}}$

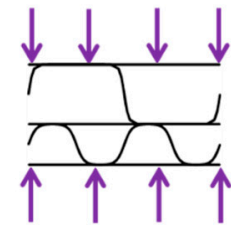

(e)

$A_{k}$

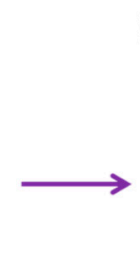

(d)

(c)

$$
\text { crushed }
$$
geometry

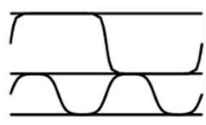

assembly

\section{K}

Figure 6. The workflow of the numerical study conducted in this study to determine the packaging compressive strength for crushed corrugated cardboard.

Intact double-walled corrugated cardboard was assumed as an input geometry to the algorithm. Part of a double-walled corrugated cardboard was simulated; namely, the section in plane was $8 \mathrm{~mm} \times 8 \mathrm{~mm}$. The fluting period for the upper layer was $8 \mathrm{~mm}$, and the fluting period for the lower layer was $4 \mathrm{~mm}$; each fluting layer's wave 'starts' from the middle of its height. Upper fluting height was equal to $4 \mathrm{~mm}$, while lower fluting height was equal to $2 \mathrm{~mm}$. The thicknesses of the liners and fluting papers were 0.29 and $0.30 \mathrm{~mm}$, respectively. The axial spacing between the outer liners was equal to $6 \mathrm{~mm}$.

The paper materials were modeled using classical elastic orthotropy. The material data were taken from the literature [24,31,32]. All material data are presented in Table 1, i.e., $E_{1}, E_{2}$, $v_{12}, G_{12}, G_{13}$ and $G_{23}$, which represent Young's moduli in both directions, Poisson's ratio and 3 shear moduli, respectively.

Table 1. Material data of intact double-walled corrugated cardboard used for modeling paper layers according to orthotropic constitutive relation.

\begin{tabular}{ccccccc}
\hline Layers & $\begin{array}{c}E_{\mathbf{1}} \\
(\mathbf{M P a})\end{array}$ & $\begin{array}{c}\boldsymbol{E}_{\mathbf{2}} \\
\mathbf{( M P a}\end{array}$ & $\begin{array}{c}v_{\mathbf{1 2}} \\
\mathbf{( - )}\end{array}$ & $\begin{array}{c}G_{\mathbf{1 2}} \\
\mathbf{( M P a}\end{array}$ & $\begin{array}{c}G_{\mathbf{1 3}} \\
(\mathbf{M P a})\end{array}$ & $\begin{array}{c}G_{\mathbf{2 3}} \\
(\mathbf{M P a})\end{array}$ \\
\hline liners & 3326 & 1694 & 0.34 & 859 & 429.5 & 429.5 \\
fluting & 2614 & 1532 & 0.32 & 724 & 362 & 362 \\
\hline
\end{tabular}

In this study, the crushed geometry of the corrugated cardboard was acquired by a simple updated numerical-analytical approach. It should be underlined that the finite element method computations were not used here. In our previous paper, i.e., [24], both approaches (finite element method and analytical) were presented and used equivalently. Here, only the updated numerical-analytical approach was used.

The updated numerical-analytical approach is represented by two components, a hyperbolic tangent and a linear correction function, and it reads:

$$
y(x)=y_{0}(x)+a x .
$$


The hyperbolic tangent component takes the following form:

$$
y_{0}(x)=\frac{\bar{H}}{2} \tanh \left(k x \frac{2 \pi}{P}\right),
$$

in which $\bar{H}$ is the crushed height of the fluting layer, $k$ is the crushing parameter found by minimizing the discrepancy between the length of the uncrushed flute and that of the crushed one (see below), $x$ is the horizontal coordinate along the cardboard machine direction, $P$ is the fluting period and $a$ is the correction parameter. Parameter $a$ adjusts $y(x)$ for small values of crushing and may be derived by the following relation:

$$
a=\frac{\left(\bar{H} / 2-y_{0}(P / 4)\right)}{P / 4} .
$$

Parameter $k$ is obtained numerically through minimization, and it requires the length of intact fluting, $L$, and the fluting length of the crushed flute shape, $\bar{L}$ :

$$
k=\min _{1<k<\infty}(L-\bar{L})
$$

These length magnitudes may be computed analytically. The length of intact fluting, $L$, takes the following form:

$$
L=\int_{-\frac{P}{4}}^{\frac{P}{4}} \sqrt{1-\left(\frac{d h}{d x}\right)^{2}} d x
$$

Intact fluting is approximated by a sinus function and takes the form:

$$
h(x)=\frac{H}{2} \sin \left(x \frac{2 \pi}{P}\right)
$$

and, after derivation, one can obtain $d h / d x$ to be used in Equation (8). For a sine-like function, the derivative is:

$$
\frac{d h}{d x}=\frac{H \pi}{P} \cos \left(x \frac{2 \pi}{P}\right) .
$$

The length of crushed fluting, $\bar{L}$, takes a form similar to Equation (8):

$$
\bar{L}=\int_{-\frac{P}{4}}^{\frac{P}{4}} \sqrt{1-\left(\frac{d y}{d x}\right)^{2}} d x .
$$

The explicit form of the crushed flute shape function, $y(x)$, reads:

$$
y(x)=\frac{\bar{H}}{2} \tanh \left(k x \frac{2 \pi}{P}\right)+a x
$$

and its derivative, $d y / d x$, takes the following form to be used in Equation (11):

$$
\frac{d y}{d x}=-k \frac{\bar{H} \pi}{P}\left(\tanh ^{2}\left(k x \frac{2 \pi}{P}\right)-1\right)+a .
$$

Parameters $k$ and $a$ must be computed for the particular case of fluting; the input parameters are $H$ and $P$. As examples, the parameters $k$ and $a$ were computed for the cardboards with $H=8 \mathrm{~mm}$ and $P=4 \mathrm{~mm}$ for various levels of crushing, from $0 \%$ to $50 \%$, and are presented in Table 2. 
Table 2. Exemplary values of due to $k$ and $a$ parameters for $H=8 \mathrm{~mm}$ and $P=4 \mathrm{~mm}$ for different levels of crushing.

\begin{tabular}{ccc}
\hline Crushing Level, CRS (\%) & $\begin{array}{c}\boldsymbol{k} \text { Parameter } \\
\mathbf{( - )}\end{array}$ & $\begin{array}{c}a \text { Parameter } \\
\mathbf{( - )}\end{array}$ \\
\hline 0 & 1.11 & 0.0238 \\
5 & 1.39 & 0.0091 \\
10 & 1.68 & 0.0028 \\
15 & 2.04 & 0.0006 \\
20 & 2.49 & 0.0001 \\
25 & 3.13 & 0 \\
30 & 4.09 & 0 \\
35 & 5.65 & 0 \\
40 & 8.58 & 0 \\
45 & 15.54 & 0 \\
50 & 45.98 & 0 \\
\hline
\end{tabular}

The discussion above refers to a single fluting layer; however, in this study, doublewalled corrugated cardboards were considered. Thus, for each of two fluting layers the crushing distribution must be determined. After experimental observations, the following crushing distribution was used.

First, let us assume that $H_{1} \geq H_{2}$. Namely, $H_{1}$ is the height of the higher fluting layer and $\mathrm{H}_{2}$ is the height of the lower fluting layer. Further, the crushing level is understood as the following:

$$
\bar{t}=t \cdot(100-C R S) / 100,
$$

in which $t$ is the total height of the intact double-walled corrugated cardboard, $\bar{t}$ is its counterpart for crushed double-walled corrugated cardboard and CRS is the total crushing level in percentages (considered before elastic relaxation of 50\%), e.g., $20 \%$.

The crushing level of the lower fluting layer, $C R S_{2}$, is computed from the following distribution, observed experimentally:

$$
C R S_{2}=C R S \cdot \frac{H_{2}}{H_{1}}
$$

in which $H_{1}$ is the height of intact higher fluting, while $H_{2}$ is the height of intact lower fluting. The height of lower fluting due to crushing, $\bar{H}_{2}$, takes the following form:

$$
\bar{H}_{2}=H_{2} \cdot\left(100-C R S_{2}\right) / 100 .
$$

Thus, now we may compute the height of higher fluting due to crushing, $\bar{H}_{1}$, by simple subtraction:

$$
\bar{H}_{1}=\bar{t}-\bar{H}_{2}
$$

and, consequently, the crushing level of higher fluting may be measured by this expression:

$$
C R S_{1}=\left(1-\frac{\bar{H}_{1}}{H_{1}}\right) \cdot 100 .
$$

Using the numerical-analytical approach discussed above to determine the crushing shape of double-walled corrugated cardboard, apart from the intact case (crushing of $0 \%$ ), three levels of crushing were assumed for further analyses, namely, $10 \%, 20 \%$ and $30 \%$ (see Figure 7). In the first column, the three-dimensional views on the representative volume elements (RVE) are presented, while in the second column, the cross-section shapes after crushing are shown. The model of the RVE of double-walled corrugated cardboard had 1728 shell elements with linear shape functions and 1925 nodes. To represent fluting periods, 64 segments were used. Segment analysis was conducted in our recent work [31], which showed that to obtain the correct transversal shear stiffnesses, the number of segments 
must be large enough. The particular crushing levels for higher and lower fluting obtained from computations (assuming that half of applied CRS recovers due to elastic relaxation) are: $6.25 \%$ and $2.5 \% ; 12.5 \%$ and $5 \%$; and $18.75 \%$ and $7.5 \%$, for a total creasing of $10 \%, 20 \%$ and $30 \%$, respectively (see Figure $7 \mathrm{c}-\mathrm{h}$ ).

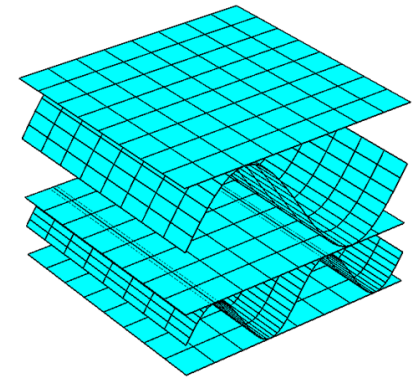

(a)

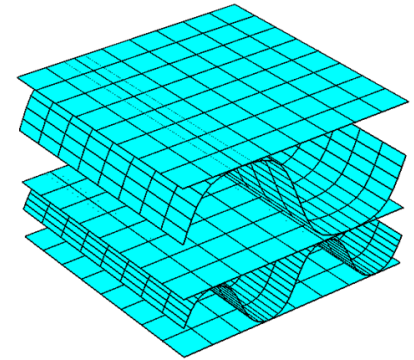

(c)

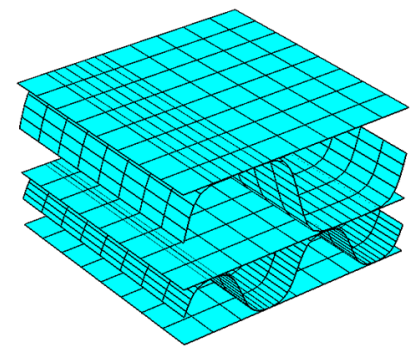

(e)

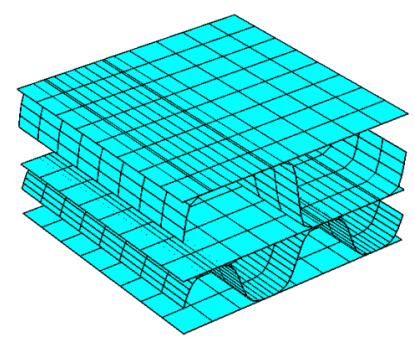

(g)

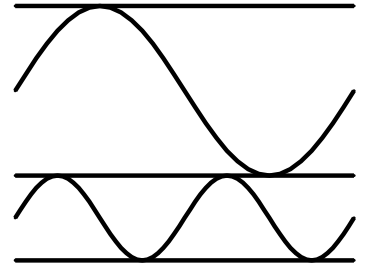

(b)

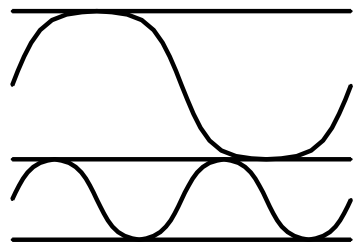

(d)

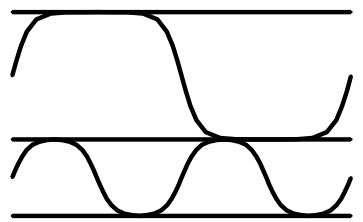

(f)

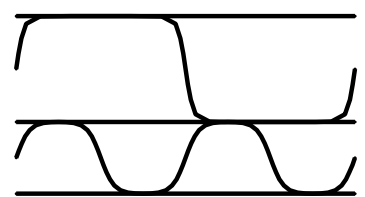

(h)

Figure 7. The crushed geometries of double-walled cardboard used in the study, obtained from the numerical-analytical approach; three-dimensional views $(\mathbf{a}, \mathbf{c}, \mathbf{e}, \mathbf{g})$ and counterpart cross-section shapes $(\mathbf{b}, \mathbf{d}, \mathbf{f}, \mathbf{h})$ for $0 \%, 10 \%, 20 \%$ and $30 \%$, respectively.

In the next stage of the study, the output geometries (without any residual stresses) were used in finite element preprocessing of in-house code to build the material stiffness matrix of the structures analyzed (see Figure $7 \mathrm{a}, \mathrm{c}, \mathrm{e}, \mathrm{g}$ ). Before this, the deterioration of the material parameter due to delamination was assumed according to [24] - the elastic parameters of selected regions were decreased. The material stiffness matrix of RVEs 
acquired with embedded orthotropic and locally deteriorated properties (due to decreasing of elastic properties) were processed by the homogenization method of Garbowski and Gajewski [31]. Other homogenization methods applied for cardboard structures are the found in the papers of Buannic et al. [33] or Biancolini [32]. One of the biggest advantages of Garbowski and Gajewski's [31] method is the possibility to compute the effective transversal shear stiffness of the input structure. The method allows for the computation of the stiffness matrix of a single laminate shell RVE based on the input structure; here, corrugated cardboards with different levels of crushing are included. In the literature, other homogenization methods may be found, for instance [34-51].

Furthermore, the output data from the homogenization were used to analytically compute the compressive strength of simple flap boxes (with various box dimensions), with different levels of crushing included. The advanced analytical approach was considered, which takes into consideration different box dimensions in plane, material orthotropy and transversal shear stiffnesses. This analytical model was reviewed in detail in our previous work [15]. Thus, only the main formulas are presented here. The compressive strength of the packaging is estimated by the following relation:

$$
B C T=2 \bar{k} E C T^{r}\left[\gamma_{b}\left(P_{c r}^{b}\right)^{1-r} b+\gamma_{c}\left(P_{c r}^{c}\right)^{1-r} c\right]
$$

in which $\bar{k}$ and $r$ are the dimensionless constants, $P_{c r}^{b}$ and $P_{c r}^{c}$ are the critical forces of box panels of width $b$ and $c$, respectively, and $\gamma_{b}$ and $\gamma_{c}$ are the reduction coefficients. Critical forces for $b$ and $c$ (box dimensions in plane) are computed according to:

$$
P_{c r}^{i}=\frac{M}{N} \frac{1}{\alpha^{2}} ; \quad i=\{b, c\},
$$

in which

$$
M=D_{11} \alpha^{4}+2\left(D_{12}+2 D_{33}\right) \alpha^{2} \beta^{2}+D_{22} \beta^{4}+\left(\frac{\alpha^{2}}{A_{44}}+\frac{\beta^{2}}{A_{55}}\right) c_{1}
$$

and

$$
N=1+\frac{c_{1}}{A_{44} A_{55}}+\frac{c_{2}}{A_{55}}+\frac{c_{3}}{A_{44}} ; \quad \alpha=\frac{m \pi}{\bar{a}} ; \quad \beta=\frac{\pi}{i} \quad ;
$$

in which $c_{1}, c_{2}, c_{3}$ and $c_{4}$ are the constants derived from boundary conditions.

The ECT value of the cardboard for Equation (19) must be determined in order to analytically compute the compressive strength of the box. Here, it was assumed for a case study, based on the experiments, to be $8 \mathrm{kN} / \mathrm{m}$. Its decrease due to crushing was computed according to the relation observed in our experimental results (see Section 3.1).

\section{Results}

\subsection{Experimental Study}

Four corrugated boards were selected for experimental study, each with a different grammage, exactly two BC flutes-BC-480 $\left(480 \mathrm{~g} / \mathrm{m}^{2}\right), \mathrm{BC}-580\left(580 \mathrm{~g} / \mathrm{m}^{2}\right)$-and two EB flutes-EB-560 $\left(560 \mathrm{~g} / \mathrm{m}^{2}\right)$, EB-670 $\left(670 \mathrm{~g} / \mathrm{m}^{2}\right)$.

The numerous tests and laboratory measurements were carried out on corrugated boards to verify: (a) bending stiffness in cross-direction (BNT-CD) and in machine direction (BNT-MD); (b) shear stiffness in cross-direction (SST-CD) and in machine direction (SST$\mathrm{MD})$; (c) torsion stiffness in cross-direction (TST-CD) and in machine direction (TST-MD); (d) sample resistance to edge crushing (ECT); and (e) sample thickness before (intact cardboard) and after crushing (THK2 and THK).

Each corrugated cardboard index was subjected to three to five series of tests for the same crushing level. The range of corrugated board crushing was from $10 \%$ to $70 \%$ of its initial thickness in increments of $10 \%$. The measurement of the thickness of the crushed specimen was carried out several minutes after crushing, to take into account the effect of elastic relaxation of the corrugated board. Selected results from the laboratory tests are summarized below. In Figures 8-11, the results of different degradation levels of the 
parameters for each of the analyzed double-walled corrugated boards are shown. The collection of experimental data allowed for computation of the regression lines for each test according to Equations (2) and (3). The values of the SST, BNT and TST are shown in a standardized way, as the ratio of the value obtained for a crushed sample with respect to the initial value (i.e., for $\mathrm{CRS}=0 \%$ ).

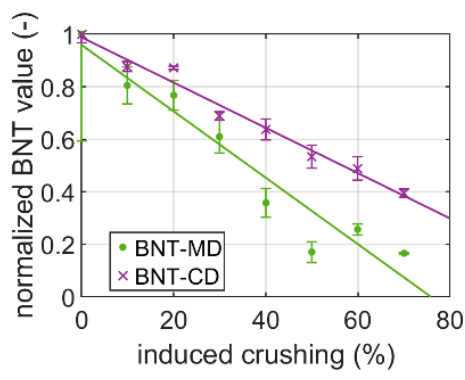

(a)

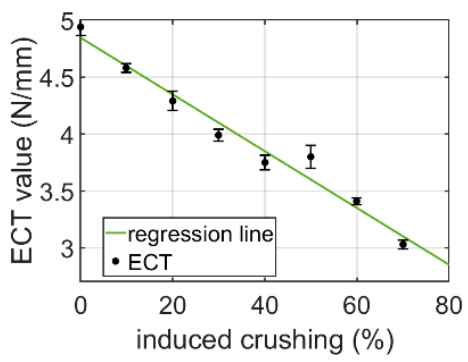

(d)

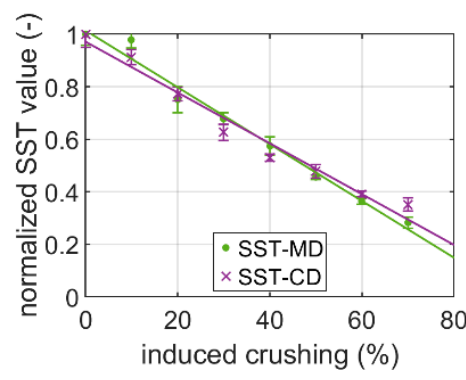

(b)

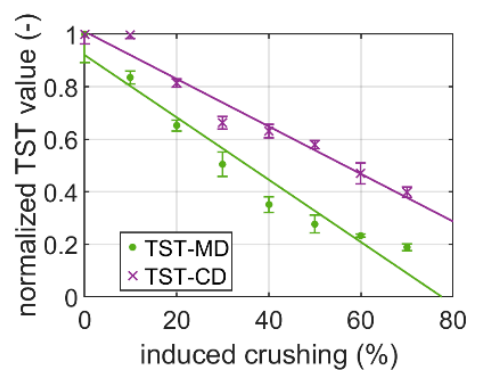

(c)

Figure 8. The decreases in measured values for BC-480 double-walled corrugated cardboard in the tests: (a) BNT; (b) SST; (c) TST; (d) ECT; (e) THK2.

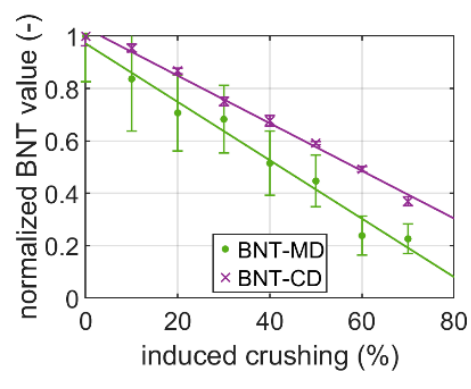

(a)

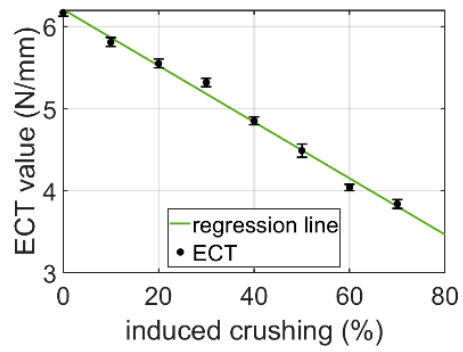

(d)

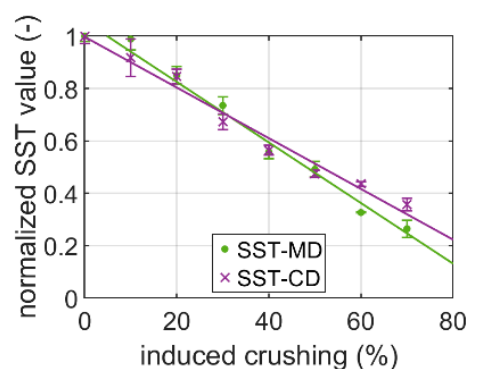

(b)

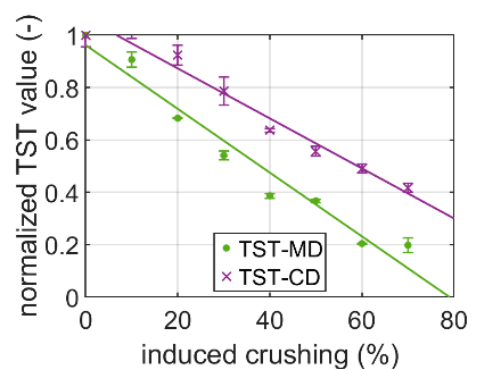

(c)

Figure 9. The decreases in measured values for BC-580 double-walled corrugated cardboard in the tests: (a) BNT; (b) SST; (c) TST; (d) ECT; (e) THK2. 


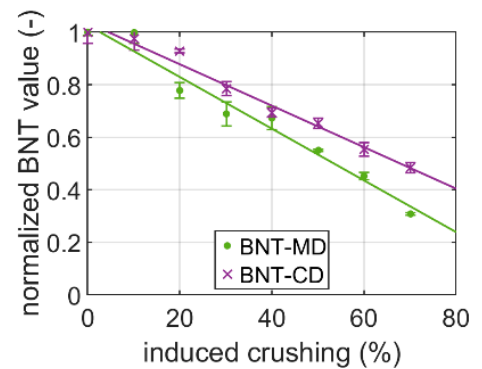

(a)

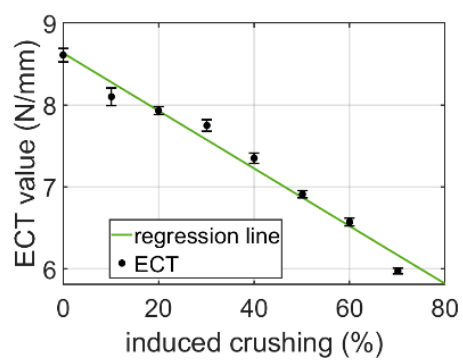

(d)

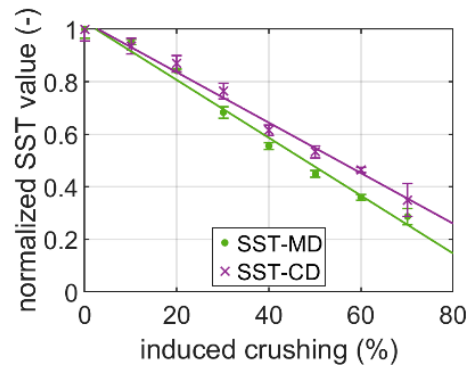

(b)

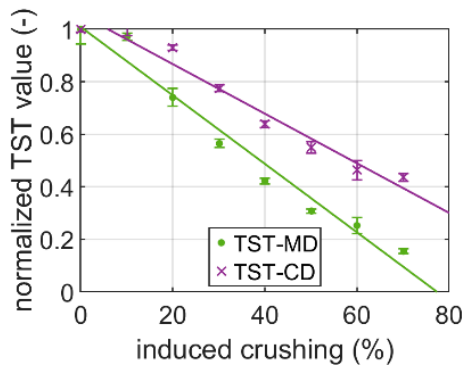

(c)

Figure 10. The decreases in measured values for EB-560 double-walled corrugated cardboard in the tests: (a) BNT; (b) SST; (c) TST; (d) ECT; (e) THK2.

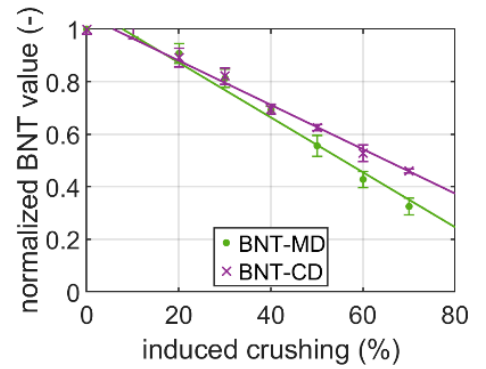

(a)

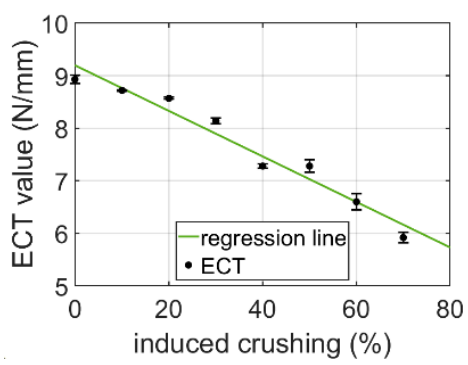

(d)

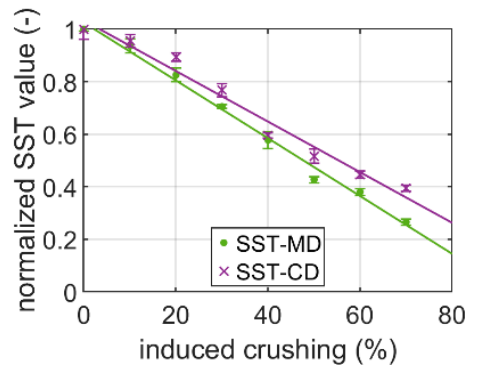

(b)

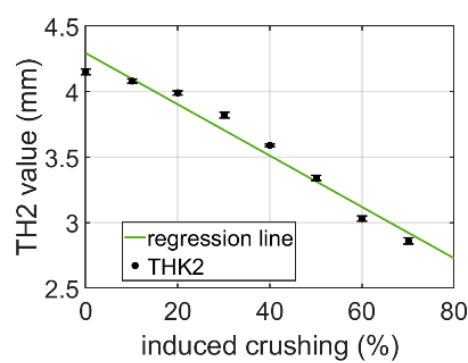

(e)

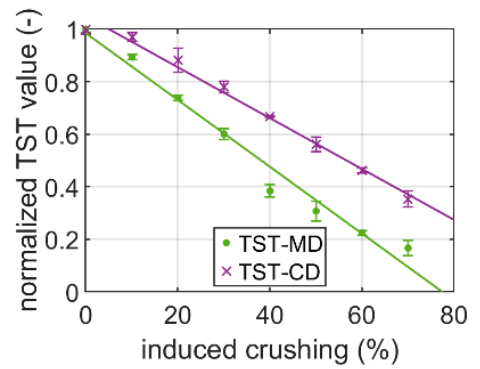

(c)

Figure 11. The decreases in measured values for EB-670 double-walled corrugated cardboard in the tests: (a) BNT; (b) SST; (c) TST; (d) ECT; (e) THK2.

In order to determine the relationship between crushing and the deterioration of measured mechanical parameters of double-walled corrugated board, the coefficient of determination for each quantity was computed according to Equation (1). The values obtained are summarized in Table 3. 
Table 3. The coefficient of determination $R^{2}$ for all corrugated cardboards considered and different measurements.

\begin{tabular}{ccccccccc}
\hline $\begin{array}{c}\text { Cardboard } \\
\text { Index }\end{array}$ & THK2 & ECT * & BNT-MD * & BNT-CD * & SST-MD * & SST-CD * & TST-MD * & TST-CD * \\
\hline BC-480 & 0.000 & 0.302 & 0.591 & 0.956 & 0.989 & 0.993 & 0.566 \\
BC-580 & 0.014 & 0.304 & 0.898 & 0.917 & 0.976 & 0.998 & 0.704 & 0.954 \\
EB-560 & 0.000 & 0.000 & 0.981 & 0.727 & 0.989 & 0.965 & 0.726 & 0.877 \\
EB-670 & 0.000 & 0.000 & 0.915 & 0.770 & 0.988 & 0.957 & 0.695 & 0.931 \\
\hline
\end{tabular}

* THK2—thickness; ECT—edge crush test; BNT—bending test; SST—shear stiffness test; TST—torsion stiffness test; MD—machine direction; $\mathrm{CD}$-cross-machine direction.

Using the mean value of the measured parameters in both the cross-machine direction (CD) and machine direction (MD) to calculate the linear regression is more accurate. Figure 12 represents the crushing line and the normalized parameter values averaged from two directions. The coefficients of determination for averaged values from two directions are shown in Table 4.

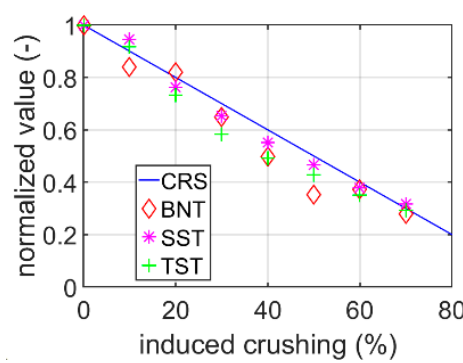

(a)

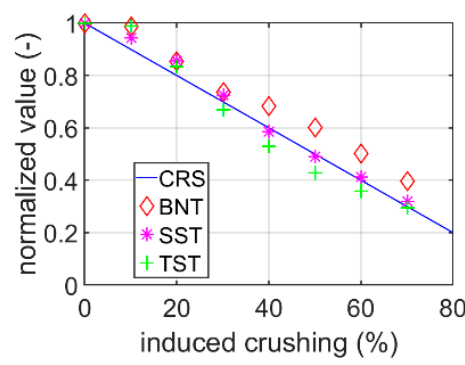

(c)

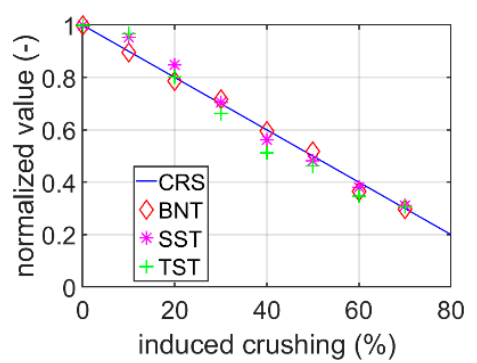

(b)

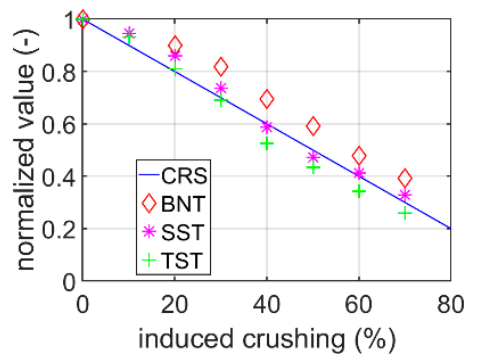

(d)

Figure 12. The decreases in measured parameters (average from the two directions' data) for doublewalled corrugated cardboards: (a) BC-480; (b) BC-580; (c) EB-560; (d) EB-670.

Table 4. The coefficient of determination $R^{2}$ due to averaging data in double direction tests for all corrugated cardboards considered.

\begin{tabular}{cccc}
\hline Cardboard Index & BNT $^{*}$ & SST $^{*}$ & TST \\
\hline BC-480 & 0.951 & 0.995 & 0.949 \\
BC-580 & 1.000 & 0.996 & 0.987 \\
EB-560 & 0.892 & 0.994 & 0.982 \\
EB-670 & 0.859 & 0.993 & 0.974 \\
\hline
\end{tabular}

* BNT—bending test; SST—shear stiffness test; TST—-torsion stiffness test.

Values of ECT and THK2 obtained from the measurements show similar trends; this is visible for all types of the samples. Thus, a reference line was adopted to describe the relationship between the deterioration of normalized parameters: ECT and THK2 and the level of crushing of the double-walled corrugated board. The reference line equation takes the following form:

$$
y=1-0.46 x
$$


where $x$-the crushing value and $y$-the normalized parameter value.

In Figure 13, the fittings of the reference line computed from Equation (23) to the normalized data of ECT and THK2 for the analysed corrugated cardboards are shown. It is worth noting that all experimental data can be approximated (with high accuracy) by linear functions, which makes it much easier to infer and build equivalent models in the next step.

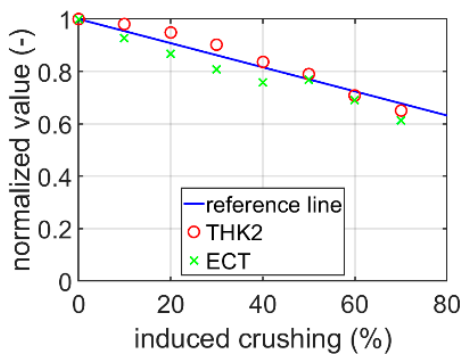

(a)

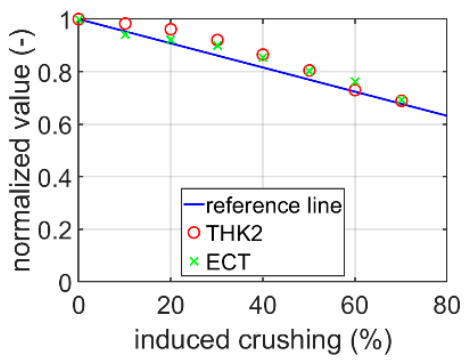

(c)

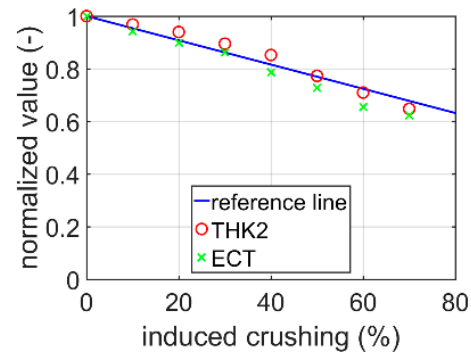

(b)

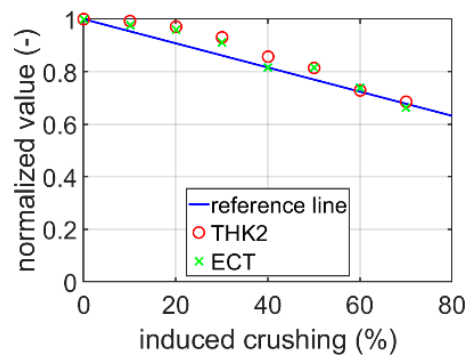

(d)

Figure 13. The decreases in normalized thickness (THK2) and edge crush test (ECT) values for double-walled corrugated cardboard with an index of: (a) BC-480; (b) BC-580; (c) EB-560; (d) EB-670.

The coefficients of determination $R^{2}$ were also calculated for the reference line and normalized ECT and THK2 values according to Equation (1) (see Table 5). In Equation (1), $x_{i}$ is the reference line value calculated from Equation (23), $\hat{y}_{i}$ is the normalized THK2 and ECT values and $\operatorname{var}(x)$ is the variance of the reference line value.

Table 5. The values of the coefficient of determination $R^{2}$ between the reference line and normalized ECT and THK2 quality.

\begin{tabular}{cc}
\hline Cardboard Index & $\boldsymbol{R}^{\mathbf{2}}$ \\
\hline BC-480 & 0.977 \\
BC-580 & 0.967 \\
EB-560 & 0.941 \\
EB-670 & 0.930 \\
\hline
\end{tabular}

\subsection{Modeling Crushing in Estimating Compressive Strength of Packaging}

The laminate shell stiffnesses were computed for three crushing levels of corrugated cardboard, in which the crushing levels were $10 \%, 20 \%$ and $30 \%$, but also for the intact cardboard ( $0 \%$ crushing). Selected values of the stiffnesses computed, required to estimate the compressive stiffnesses of the packaging according to Equation (19), are presented in Table 6. Additionally, the values of ECT computed according to Equation (23) for different levels of crushing are presented in the same table in the last row. 
Table 6. The computed stiffnesses of the representative shell element computed for different levels of crushing of double-walled corrugated cardboard.

\begin{tabular}{ccccc}
\hline & 0\% Crushing & $\mathbf{1 0 \%}$ Crushing & $\mathbf{2 0 \%}$ Crushing & 30\% Crushing \\
\hline$D_{11}\left(\mathrm{~Pa} \cdot \mathrm{m}^{3}\right)$ & 19,514 & 17,598 & 15,751 & 14,006 \\
$D_{22}\left(\mathrm{~Pa} \cdot \mathrm{m}^{3}\right)$ & 14,326 & 12,759 & 11,273 & 9876 \\
$D_{12}\left(\mathrm{~Pa} \cdot \mathrm{m}^{3}\right)$ & 3438 & 3094 & 2763 & 2453 \\
$D_{33}\left(\mathrm{~Pa} \cdot \mathrm{m}^{3}\right)$ & 5629 & 5069 & 4517 & 3993 \\
$A_{44}(\mathrm{~Pa} \cdot \mathrm{m})$ & 77.3 & 52.1 & 39.5 & 30.5 \\
$A_{55}(\mathrm{~Pa} \cdot \mathrm{m})$ & 237.0 & 211.7 & 187.6 & 164.7 \\
$\mathrm{ECT}(\mathrm{kN} / \mathrm{m})$ & 8.0 & 7.6 & 7.2 & 6.8 \\
\hline
\end{tabular}

The main aim of the numerical part of the study was to determine the influence of the particular level of crushing of double-walled corrugated cardboard packaging on its compressive strength. Therefore, various dimensions of large corrugated cardboard boxes were selected and computed according to the analytical approach presented in Equation (19). Typical flap boxes were analyzed. The boxes' dimensions from $500 \mathrm{~mm}$ to $1000 \mathrm{~mm}$ were assumed to obtain the following ratios of box dimensions in plane: 1:1, 1:2, 1:3, 1:4, 1:5 and 2:3. Three heights of boxes were considered, i.e., $500 \mathrm{~mm}, 750 \mathrm{~mm}$ and $1000 \mathrm{~mm}$. The input data of boxes' dimensions and the compressive strength for different levels of crushing are presented in Table 7.

Table 7. The dimensions of the boxes considered in the numerical study of the paper and the resulting compressive box strength for different levels of crushing.

\begin{tabular}{|c|c|c|c|c|c|c|}
\hline \multicolumn{3}{|c|}{ Box Dimensions } & \multicolumn{4}{|c|}{$\begin{array}{l}\text { Box Compressive Strength Due to Crushed } \\
\text { Cardboard }\end{array}$} \\
\hline $\begin{array}{c}\mathrm{b} \\
(\mathrm{mm})\end{array}$ & $\begin{array}{c}\mathrm{c} \\
(\mathrm{mm})\end{array}$ & $\begin{array}{c}\mathrm{a} \\
(\mathrm{mm})\end{array}$ & $\begin{array}{c}0 \% \\
\text { Crushing } \\
\text { (N) }\end{array}$ & $\begin{array}{c}10 \% \\
\text { Crushing } \\
(\mathrm{N})\end{array}$ & $\begin{array}{c}20 \% \\
\text { Crushing } \\
\text { (N) }\end{array}$ & $\begin{array}{c}30 \% \\
\text { Crushing } \\
\text { (N) }\end{array}$ \\
\hline 500 & 500 & 500 & 6001 & 5613 & 5227 & 4848 \\
\hline 500 & 1000 & 500 & 6933 & 6490 & 6049 & 5616 \\
\hline 300 & 900 & 500 & 5805 & 5433 & 5064 & 4701 \\
\hline 250 & 1000 & 500 & 5894 & 5516 & 5141 & 4772 \\
\hline 200 & 1000 & 500 & 5685 & 5320 & 4958 & 4602 \\
\hline 600 & 900 & 500 & 7132 & 6676 & 6223 & 5777 \\
\hline 500 & 500 & 750 & 6177 & 5773 & 5373 & 4979 \\
\hline 500 & 1000 & 750 & 6469 & 6052 & 5638 & 5230 \\
\hline 300 & 900 & 750 & 5378 & 5031 & 4686 & 4347 \\
\hline 250 & 1000 & 750 & 5367 & 5021 & 4679 & 4341 \\
\hline 200 & 1000 & 750 & 5156 & 4824 & 4494 & 4170 \\
\hline 600 & 900 & 750 & 6686 & 6256 & 5828 & 5406 \\
\hline 500 & 500 & 1000 & 6001 & 5613 & 5227 & 4848 \\
\hline 500 & 1000 & 1000 & 6257 & 5854 & 5453 & 5059 \\
\hline 300 & 900 & 1000 & 5295 & 4952 & 4611 & 4276 \\
\hline 250 & 1000 & 1000 & 5218 & 4880 & 4545 & 4215 \\
\hline 200 & 1000 & 1000 & 5004 & 4680 & 4358 & 4042 \\
\hline 600 & 900 & 1000 & 6646 & 6218 & 5793 & 5373 \\
\hline
\end{tabular}

\section{Discussion}

In the experimental part of this research, the relation between intentionally induced crushing (CRS) of double-walled corrugated cardboard and the output from mechanical laboratory tests of the cardboard was studied (see Figures 8-11). Four types of fluting compositions of double-walled corrugated cardboards were analyzed, two $\mathrm{BC}$ and two EB cardboards. The coefficients of determination were computed for all measurements, namely, thickness, ECT, bending (BNT), shearing (SST) and twisting (TST), the later three in $\mathrm{CD}$ and MD (see Tables 3-5). The highest determination ratios were obtained for corrugated 
cardboard of $\mathrm{BC}-580$. If the mean values from $\mathrm{CD}$ and $\mathrm{MD}$ are considered, the highest determination ratios were observed in the SST (0.995) in comparison to the BNT (0.926) and TST (0.973). This means that the SST is able to predict the crushing of the cardboard best in our controlled experimental study. Similar conclusions were obtained for single-walled corrugated cardboards [24]. Regression lines were also computed for each measurement type (see Figures 12 and 13). For the ECT and thickness measurements, the reference line equation was derived, from which it may be concluded that the particular percentage level of crushing reduces those magnitudes of ECT and thickness measured with $46 \%$ of the crushing level.

In the numerical part of the study, intact and crushed cardboard was investigated, in particular the decrease in its laminate stiffness properties and the decrease in the packaging's compressive strength. It appeared that, for instance, if one compares intact cardboard ( $0 \%$ crushing) and the $30 \%$ crushing case, the decreases in almost all effective stiffnesses are about $29 \%$ (see Table 6). Only for $A_{44}$ is the decrease about twice that, i.e., $61 \%$. A similar outcome was obtained for $10 \%$ and $20 \%$ crushing, but the drops are proportionally lower.

The compressive strengths of the packaging samples are presented in Table 7. It may be observed that the values of compressive strength for intact corrugated cardboard $(0 \%$ crushing) are between about $5000 \mathrm{~N}$ and $7100 \mathrm{~N}$. The values for $10 \%$ crushing are between $4700 \mathrm{~N}$ and $6700 \mathrm{~N}$. The values for $20 \%$ crushing are between $4400 \mathrm{~N}$ and $6200 \mathrm{~N}$. The values for $30 \%$ crushing are between $4000 \mathrm{~N}$ and $5800 \mathrm{~N}$. The results for crushing of $10 \%$, $20 \%$ and $30 \%$ referring to the results for intact corrugated cardboard packaging give almost the same percentage differences if one considers row to row values, i.e., between different box dimensions. In conclusion, the drop in compressive strength of the packaging due to crushing is not sensitive to box dimensions.

Furthermore, the results show that if one compares the results for a box with intact corrugated cardboard with the results for a crushed one at $10 \%, 20 \%$ or $30 \%$, the percentage differences are $6.4 \%, 12.8 \%$ and $19.1 \%$, respectively. For instance, in the last case, namely, the $600 \mathrm{~mm} \times 900 \mathrm{~mm} \times 1000 \mathrm{~mm}$ box, the compressive strength of the packaging with intact corrugated cardboard is $6646 \mathrm{~N}$; the compressive strength of the packaging with the same cardboard but crushed $30 \%$ is $5373 \mathrm{~N}$; the percentage difference for those values is $19.2 \%$. Notice that the relation between crushing level and percentage drop is almost linear and may be approximated by a factor of $16 / 25$. For instance, if the crushing is equal to $25 \%$, the drop in packaging compressive strength would be $25 \% \cdot 16 / 25=16 \%$.

The numerical modeling presented here may be used for estimating the influence of the crushed corrugated cardboard on the packaging compressive strength for cardboards with other shapes of fluting without the use of finite element analysis, based on the precise crushing estimation by the SST.

\section{Conclusions}

In this study, a series of mechanical tests were carried out on various double-walled corrugated cardboards. In these tests, the effect of intentional and fully controlled crushing introduced to the samples in the range from 10 to $70 \%$ was investigated. Based on experimental observations, an analytical crush model was proposed and then homogenized using the RVE finite element stiffness matrix and techniques and the strain equivalence approach Ultimately homogenized, crushed corrugated cardboard samples were used in a theoretical case study to understand the influence of a certain level of crush on the performance of the different flap boxes. It was observed that there are simple linear relationships between the deteriorating measured values and the amount of crush; a similar relationship was observed between the load-bearing capacity of the selected flap boxes and the degree of crushing of the corrugated cardboard.

All these observations lead to one major conclusion. The crushing of corrugated cardboard has a significant impact on the mechanical properties of the cardboard; it is always present in the production process, and it cannot be avoided as long as the analog machines for die-cutting and printing are not replaced by digital tools. Digital machines, e.g., laser 
finishing and digital printing techniques, do not damage the corrugated cardboard. When the corrugated cardboard is damaged, its mechanical properties are naturally weakened, which leads to a lower load-bearing capacity. Using the techniques presented in our work, it is possible not only to control the amount of crushing, but also to estimate the impact of the investigated crushing on the load capacity of the packaging. Thanks to this, it is possible to use the proposed measurement techniques and numerical and analytical tools in the process of controlling the production of corrugated board for transport packaging.

Author Contributions: Conceptualization, T.G. (Tomasz Garbowski); methodology, T.G. (Tomasz Garbowski); software, T.G. (Tomasz Garbowski), T.G. (Tomasz Gajewski); validation, T.G. (Tomasz Garbowski), T.G. (Tomasz Gajewski), N.S.; formal analysis, T.G. (Tomasz Garbowski), T.G. (Tomasz Gajewski), N.S.; investigation, T.G. (Tomasz Garbowski), T.G. (Tomasz Gajewski), N.S., M.K.; writingoriginal draft preparation, T.G. (Tomasz Garbowski), T.G. (Tomasz Gajewski), N.S.; writing—review and editing, T.G. (Tomasz Garbowski), T.G. (Tomasz Gajewski), M.K.; visualization, T.G. (Tomasz Gajewski), T.G. (Tomasz Garbowski) and N.S.; supervision, T.G. (Tomasz Garbowski); project administration, T.G. (Tomasz Garbowski); funding acquisition, M.K. All authors have read and agreed to the published version of the manuscript.

Funding: The APC was funded by the National Center for Research and Development, Poland, grant at Schumacher Packaging Sp. z o. o., grant number POIR.01.01.01-00-1006/19.

Institutional Review Board Statement: Not applicable.

Informed Consent Statement: Not applicable.

Data Availability Statement: The data presented in this study are available on request from the corresponding author.

Acknowledgments: The authors thank AQUILA VPK Wrzesnia for providing samples of corrugated cardboard for the study. The authors also thank Femat Sp. z o. o. for providing the laboratory equipment.

Conflicts of Interest: The authors declare no conflict of interest. The funders had no role in the design of the study; in the collection, analyses, or interpretation of data; in the writing of the manuscript, or in the decision to publish the results.

\section{References}

1. Garbowski, T.; Gajewski, T.; Grabski, J.K. Estimation of the Compressive Strength of Corrugated Cardboard Boxes with Various Openings. Energies 2021, 14, 155. [CrossRef]

2. Fadiji, T.; Ambaw, A.; Coetzee, C.J.; Berry, T.M.; Opara, U.L. Application of the finite element analysis to predict the mechanical 490 strength of ventilated corrugated paperboard packaging for handling fresh produce. Biosyst. Eng. 2018, 174, $260-281$. [CrossRef]

3. Garbowski, T.; Gajewski, T.; Grabski, J.K. Estimation of the Compressive Strength of Corrugated Cardboard Boxes with Various Perforations. Energies 2021, 14, 1095. [CrossRef]

4. Gallo, J.; Cortés, F.; Alberdi, E.; Goti, A. Mechanical Behavior Modeling of Containers and Octabins Made of Corrugated Cardboard Subjected to Vertical Stacking Loads. Materials 2021, 14, 2392. [CrossRef]

5. Henry, W.; Haslach, J.R. The moisture and rate-dependent mechanical properties of paper: A review. Mech. Time Depend. Mater. 2000, 4, 169-210. [CrossRef]

6. Östlund, S. Three-dimensional deformation and damage mechanisms in forming of advanced structures in paper. In Advances in Pulp and Paper Research; Batchelor, W., Söderberg, D., Eds.; FRC: Manchester, UK, 2018; pp. 489-594. [CrossRef]

7. Shick, P.E.; Chari, N.C.S. Top-to-bottom compression for double wall corrugated boxes. TAPPI J. 1965, 48, 423-430.

8. Chen, J.; Zhang, Y.; Sun, J. An overview of the reducing principle of design of corrugated box used in goods packaging. Procedia Environ. Sci. 2011, 10, 992-998. [CrossRef]

9. Pathare, P.B.; Opara, U.L. Structural design of corrugated boxes for horticultural produce: A review. Biosyst. Eng. 2014, 125, 128-140. [CrossRef]

10. Wolf, M. New equation helps pin down box specifications. Package Eng. 1972, 17, 66-67.

11. McKee, R.C.; Gander, J.W.; Wachuta, J.R. Compression strength formula for corrugated boxes. Paperboard Packag. 1963, 48, 149-159.

12. Batelka, J.J.; Smith, C.N. Package Compression Model. IPST Project 3746, Final Report; Institute of Paper Science and Technology: Atlanta, GA, USA, 1993.

13. Urbanik, T.J.; Frank, B. B. Box compression analysis of world-wide data spanning 46 years. Wood Fiber. Sci. 2006, 38, 399-416. 
14. Ristinmaa, M.; Ottosen, N.S.; Korin, C. Analytical Prediction of Package Collapse Loads-Basic considerations. Nord. Pulp Pap. Res. J. 2012, 27, 806-813. [CrossRef]

15. Garbowski, T.; Gajewski, T.; Grabski, J.K. The role of buckling in the estimation of compressive strength of corrugated cardboard boxes. Materials 2020, 13, 4578. [CrossRef] [PubMed]

16. Schrampfer, K.E.; Whitsitt, W.J.; Baum, G.A. Combined Board Edge Crush (ECT) Technology; Institute of Paper Chemistry: Appleton, WI, USA, 1987.

17. Nordstrand, T.; Carlssoon, L.A. Evaluation of transverse shear stiffness of structural core sandwich plates. Compos. Struct. 1997, 37, 145-153. [CrossRef]

18. Nordstrand, T. Basic Testing and Strength Design of Corrugated Board and Containers. Ph.D. Thesis, Lund University, Lund, Sweden, 2003.

19. Popil, R.E.; Coffin, D.W.; Habeger, C.C. Transverse shear measurement for corrugated board and its significance. Appita J. 2008, 61,307-312.

20. Avilés, F.; Couoh-Solís, F.; Carlsson, L.A.; Hernández-Pérez, A. Experimental determination of torsion and shear properties of sandwich panels and laminated composites by the plate twist test. Compos. Struct. 2011, 93, 1923-1928. [CrossRef]

21. Avilés, F.; Carlsson, L.A.; May-Pat, A. A shear-corrected formulation for the sandwich twist specimen. Exp. Mech. 2012, 52, 17-23. [CrossRef]

22. Garbowski, T.; Gajewski, T.; Grabski, J.K. Torsional and Transversal Stiffness of Orthotropic Sandwich Panels. Materials 2020, 13, 5016. [CrossRef]

23. Garbowski, T.; Gajewski, T.; Grabski, J.K. Role of transverse shear modulus in the performance of corrugated materials. Materials 2020, 13, 3791. [CrossRef]

24. Garbowski, T.; Gajewski, T.; Mrówczyński, D.; Jędrzejczak, R. Crushing of Single-Walled Corrugated Board during Converting: Experimental and Numerical Study. Energies 2021, 14, 3203. [CrossRef]

25. Jamsari, M.A.; Kueh, C.; Gray-Stuart, E.M.; Dahm, K.; Bronlund, J.E. Modelling the impact of crushing on the strength performance of corrugated fibreboard. Packag. Technol. Sci. 2020, 33, 159-170. [CrossRef]

26. Jamsari, M.A.; Kueh, C.; Gray-Stuart, E.; Martinez-Hermosilla, G.A.; Dahm, K.; Bronlund, J.E. A technique to quantify morphological damage of the flute profile in the midplane of corrugated fibreboard. Packag. Technol. Sci. 2019, 32, 213-226. [CrossRef]

27. Martinez-Hermosilla, G.A.; Kueh, C.; Dahm, K.; Bronlund, J.E. Combined modelling methodology for optimisation of box design based on hybrid genetic algorithm. Packag. Technol. Sci. 2018, 31, 709-722. [CrossRef]

28. Berry, T.M.; Fadji, T.S.; Defraeyea, T.; Opara, U.L. The role of horticultural carton vent hole design on cooling efficiency and compressions trength: A multi-parameter approach. Postharvest Biol. Technol. 2017, 124, 62-67. [CrossRef]

29. FEMat Systems-BSE. Available online: http:/ / fematsystems.pl/bse-system_en/ (accessed on 15 May 2021).

30. FEMat Systems-CRS. Available online: http:/ / fematsystems.pl/crs_en/ (accessed on 15 May 2021).

31. Garbowski, T.; Gajewski, T. Determination of transverse shear stiffness of sandwich panels with a corrugated core by numerical homogenization. Materials 2021, 14, 1976. [CrossRef] [PubMed]

32. Biancolini, M.E. Evaluation of equivalent stiffness properties of corrugated board. Compos. Struct. 2005, 69, 322-328. [CrossRef]

33. Buannic, N.; Cartraud, P.; Quesnel, T. Homogenization of corrugated core sandwich panels. Compos. Struct. 2003, 59, 299-312. [CrossRef]

34. Ramirez-Torres, A.; Penta, R.; Rodriguez-Ramos, R.; Grillo, A. Effective properties of hierarchical fiber-reinforced composites via a three-scale asymptotic homogenization approach. Math. Mech. Solids 2019, 24. [CrossRef]

35. Ramírez-Torres, A.; Penta, R.; Rodríguez-Ramos, R.; Merodio, J.; Sabina, F.J; Bravo-Castillero, J.; Guinovart-Díaz, R.; Preziosi, L.; Grillo, A. Three scales asymptotic homogenization and its application to layered hierarchical hard tissues. Int. J. Solids Struct. 2018, 130-131, 190-198. [CrossRef]

36. Ramírez-Torres, A.; Di Stefano, S.; Grillo, A.; Rodríguez-Ramos, R.; Merodio, J.; Penta, R. An asymptotic homogenization approach to the microstructural evolution of heterogeneous media. Int. J. Non Linear Mech. 2018, 106, 245-257. [CrossRef]

37. Jian, Z.; Hengyang, L.; Gengdong, C.; Yuanwu, C. On predicting the effective elastic properties of polymer nanocomposites by novel numerical implementation of asymptotic homogenization method. Compos. Struct. 2016, 135, 297-305. [CrossRef]

38. Yuanwu, C.; Liang, X.; Gengdong, C. Novel numerical implementation of asymptotic homogenization method for periodic plate structures. Int. J. Solids Struct. 2014, 51, 284-292. [CrossRef]

39. Gengdong, C.; Yuanwu, C.; Liang, X. Novel implementation of homogenization method to predict effective properties of periodic materials. Acta Mech. Sin. 2013, 29, 550-556.

40. Marek, A.; Garbowski, T. Homogenization of sandwich panels. Comput. Assist. Methods Eng. Sci. 2015, 22, 39-50.

41. Xin, L.; Khizar, R.; Peng, B.; Wenbin, Y. Two-Step Homogenization of Textile Composites Using Mechanics of Structure Genome. Compos. Struct. 2017, 171, 252-262. [CrossRef]

42. Garbowski, T.; Jarmuszczak, M. Homogenization of corrugated paperboard. Part 2. Numerical homogenization. Pol. Pap. Rev. 2014, 70, 390-394. (In Polish)

43. Garbowski, T.; Jarmuszczak, M. Numerical strength estimate of corrugated board packages. Part 1. Theoretical assumptions in numerical modeling of paperboard packages. Pol. Pap. Rev. 2014, 70, 219-222. (In Polish) 
44. Garbowski, T.; Jarmuszczak, M. Numerical strength estimate of corrugated board packages. Part 2. Experimental tests and numerical analysis of paperboard packages. Pol. Pap. Rev. 2014, 70, 277-281. (In Polish)

45. Maier, G.; Bolzon, G.; Buljak, V.; Garbowski, T.; Miller, B. Synergic Combinations of Computational Methods and Experiments for Structural Diagnoses. In Computer Methods in Mechanics. Advanced Structured Materials; Kuczma, M., Wilmanski, K., Eds.; Springer: Berlin/Heidelberg, Germany, 2010; Volume 1, pp. 453-476. [CrossRef]

46. Aboura, Z.; Talbi, N.; Allaoui, S.; Benzeggagh, M.L. Elastic behaviour of corrugated cardboard: Experiments and modeling. Compos. Struct. 2004, 63, 53-62. [CrossRef]

47. Talbi, N.; Batti, A.; Ayad, R.; Guo, Y.Q. An analytical homogenization model for finite element modelling of corrugated cardboard. Compos. Struct. 2009, 88, 280-289. [CrossRef]

48. Miehe, C.; Koch, A. Computational micro-to-macro transitions of discretized microstructures undergoing small strains. Arch. Appl. Mech. 2002, 72, 300-317. [CrossRef]

49. Lebée, A.; Sab, K. Homogenization of thick periodic plates: Application of the Bending-Gradient plate theory to a folded core sandwich panel. Int. J. Solids Struct. 2012, 49, 2778-2792. [CrossRef]

50. Lebée, A.; Sab, K. Homogenization of cellular sandwich panels. Comptes Rendus Mec. 2012, 340, 320-337. [CrossRef]

51. Ma, Y.; Xu, B.; Chen, M.; He, R.; Wen, W.; Cheng, T.; Fang, D. Optimization design of built-up thermal protection system based on validation of corrugated core homogenization. Appl. Therm. Eng. 2017, 3. [CrossRef] 